\title{
A NOTE ON SPANISH WORDS AND ON WEIGHTS, MEASURES, AND CURRENCY
}

Throughout the text, the spelling of Spanish proper nouns follows the original, with these exceptions: first names of persons and names of places and mines are modernized; in accordance with present-day usage, accents are added where pronunciation demands. In quotations and bibliographical citations, however, the original form, including the use of diacritical marks, is retained.

Spanish words that have become Anglicized are neither accented nor italicized in the text. Spanish words, particularly mining terms, for which there are no adequate English equivalents, are italicized throughout and are explained the first time they appear.

In the documents on which this study is based, weights, measures, and currency are expressed in widely different terms. Without some standardization of terminology, references to depths and location of mines and to production, costs, and profit or loss would be confusing and comparisons difficult. Current American usage is therefore followed for the most part, the original terms being maintained only when appropriate in their context.

For the period covered by the main body of this study, 1824 1849, the Mexican peso and the American dollar were approximately equal in value; the British pound was worth about five pesos or dollars. The symbol \$, which could mean either Mexican pesos or American dollars, signifies the latter throughout.

Some of the conversions to American units of weight, measure, and currency are probably not without a degree of error, owing to 
xvi

Note on Spanish Words

short-term fluctuations in exchange rates and to variations in the meaning of certain terms. In the calculation of United States equivalents, therefore, the time and place in which terms were used have been taken into account. 